\title{
Mental distress, alcohol use and help-seeking among medical and business students: a cross- sectional comparative study
}

\author{
Marie Dahlin ${ }^{1 *}$, Caroline Nilsson², Emelie Stotzer ${ }^{3}$ and Bo Runeson ${ }^{1}$
}

\begin{abstract}
Background: Stress and distress among medical students are thoroughly studied and presumed to be particularly high, but comparative studies including other student groups are rare.

Methods: A web-based survey was distributed to 500 medical students and 500 business students. We compared levels of study stress (HESI), burnout (OLBI), alcohol habits (AUDIT) and depression (MDI), and analysed their relationship with self-assessed mental health problems by logistic regression, with respect to gender.

Results: Medical students' response rate was $81.6 \%$ and that of business students $69.4 \%$. Business students scored higher on several study stress factors and on disengagement. Depression (OR 0.61, $\mathrm{Cl}_{95}$ 0.37;0.98) and harmful alcohol use (OR 0.55, $\mathrm{Cl}_{95}$ 0.37; 0.75) were both less common among medical students. However, harmful alcohol use was highly prevalent among male students in both groups (medical students 28.0\%, business students 35.4\%), and among female business students (25.0\%). Mental health problems in need of treatment were equally common in both groups; $22.1 \%$ and 19.3\%, respectively, and was associated with female sex (OR 2.01, $\mathrm{Cl}_{95}$ 1.32;3.04), exhaustion (OR 2.56, $\mathrm{Cl}_{95}$ 1.60;4.10), lower commitment to studies (OR 1.95, $\mathrm{Cl}_{95}$ 1.09;3.51) and financial concerns (OR $1.81 \mathrm{Cl}_{95}$ 1.18;2.80)

Conclusions: Medical students may not be more stressed than other high achieving student populations. The more cohesive structure of medical school and a higher awareness of a healthy lifestyle may be beneficial factors.
\end{abstract}

\section{Background}

Medical students are thoroughly investigated with regard to stress and mental health, and often suggested to be especially subject to stress and also depression [1-3]. Along with these findings, it has been argued that medical education is particularly stressful, but also that medical students carry certain personality traits such as perfectionism or performance-based self-esteem, that make them vulnerable to mental distress $[4,5]$. We have previously shown that self-rated depression is more common among Swedish medical students than in the general population [3]. Further, some studies report more distress among female medical students than their male peers [3,6], which is in accordance with a higher depression rate for women in the general population.

\footnotetext{
* Correspondence: marie.dahlin@ki.se

'Department of Clinical Neuroscience, Centre of Psychiatric Research, St.

Goran, Karolinska Institutet, Stockholm, Sweden Full list of author information is available at the end of the article
}

Mental health among young people is declining, shown by e.g. increased use of psychiatric emergency care and psychotropic medication [7,8]; and higher education may be a risk factor in itself [9]. Comparisons of medical students with other university student populations are surprisingly rare, but a few can be traced. A British study showed that medical students had no higher levels of health-anxiety and worry than students of English and Law [10], and a Canadian study found that medical students were less distressed than undergraduate law students and graduate students, respectively [11]. Two studies, from Sweden and Turkey respectively, have reported higher levels of distress among medical students compared to other university student populations $[6,12]$.

Further, medical students have been suggested to be reluctant to seek help and (as is also true for medical professionals [13]) tend to by-pass the "regular" healthcare system or avoid formal consultations $[14,15]$. We
C Biomed Central 
have only found one comparative study of students, where both psychology students and medical students reported worries about consulting a doctor for psychological problems, with regard to possible future professional dealings with that person. Medical students, in contrast to those studying psychology, had the same concerns if they were to seek help for somatic complaints [16].

We wanted to evaluate medical students' distress and mental problems in need of treatment against another student population with presumed comparative levels of study demands. In this cross-sectional survey, we compared study stress, burnout levels and mental health indicators as well as help-seeking behaviour between students at the medical school at Karolinska Institutet (KI), and the business programme at Stockholm School of Economics (SSE), both Stockholm, Sweden. Considering previous findings on medical students, we also wanted to address possible gender effects. The choice of comparison sample was based on the assumption that the groups were fairly homogenous and that the two universities attract students of similar characteristics. There is hard competition for admission to both programmes and high status attached to the medical profession as well as the expected careers of the SSE students, and both universities are considered highly prestigious. The gender distribution also corresponds fairly well, all of which supports the validity of this comparative study.

\section{Methods \\ Setting}

Higher education in Sweden is tuition free. All students are also entitled to general financial aid, composed of loans and minor grants. The student financial aid is limited to six years, which may cause students problems at the end of long programmes.

At Karolinska Institutet about 130 students are admitted twice a year to enter the medical programme of 5.5 years. All Swedish universities admit students in national competition based on upper secondary school marks or the Swedish Scholastic Assessment Test (SweSAT), a general knowledge test focusing on mathematics as well as Swedish and English comprehension. Besides these traditional ways of admittance, at KI two thirds of the positions are filled through selection from a cognitive test and interviews conducted locally. The curriculum is fixed and the students thus follow a set course of studies. At the time of the study, the curriculum followed a traditional Flexnerian model, with set courses in pre-clinical (semesters 1-5) and clinical stages (semesters 6-11). There are no graded marks at any stages of medical school in Sweden, only pass or fail, for preclinical and clinical courses alike and whether examined by written tests, OSCE's or as an evaluation of clinical rotation.

Stockholm School of Economics is a private university with an annual intake of around 300 students entering a four-year Master of Science in Economics and Business. Admission for $75 \%$ of the students at SSE is based on the upper secondary school marks, and 15\% on the SweSAT. The final $10 \%$ are admitted on distinguished achievements. During the first two years, the basic stage, all of the students take the same courses in Basic Economics and Business Administration, but by choice of order. These years are followed by two years of specialisation. During the basic stage, teaching methods are largely based on didactic lectures, but change to more project-based learning in the last two years. Unlike KI, SSE at the time of the study had a four-grade marking scale.

\section{Subjects}

The study population consisted of all students enrolled at the business programme of Stockholm School of Economics (SSE), approximately 1100 , and the medical programme at Karolinska Institutet (KI), Stockholm, approximately 1400 , in the autumn semester of 2006 . A total of 1000 students were randomly drawn from the universities' registers of active students of all stages in October 2006, 500 from each site, in order to obtain samples of similar size from both schools. The samples were recruited from early (preclinical/basic) and late (clinical/advanced) stages of the curriculum, by an equal number of 250 students. No formal power estimation was performed, but the sample size was assumed to reveal group differences over site and sex with regard to depression, with an expected point prevalence of $5 \%$. Email addresses and postal addresses were available. Seven students from SSE were excluded, three since they had terminated their studies, three studied elsewhere and one was unreachable via e-mail or mail.

The study was conducted from November until the end of December 2006 when no general examination periods were held at SSE, since such periods are not employed at KI. We sent e-mails to the included students, containing information about the study and a link to a web-based questionnaire (Websurvey ${ }^{\mathrm{TM}}$ software), which could only be filled out if subjects had ticked a box giving their informed consent. The software provided identified information on response status, but yielded a response database that was entirely anonymised. We sent out three reminders to the KI students and four to the SSE students to improve the difference in response rate. In addition, a letter with a paper questionnaire was sent by ordinary mail to 179 SSE students who had not replied. All respondents received a cinema voucher. 
The Board of Research Ethics at Karolinska Institutet assessed the study and judged that no formal ethical approval was required according to Swedish regulations. Ethical principles were adhered to. The invited students were informed that participation in the study was entirely optional and there was no possibility to identify responders of the electronic survey. The responses of the questionnaires sent in paper-format were registered upon reception and subsequently entered anonymously into the data set.

\section{Measures}

Respondents were asked to fill out gender, age, cohabiting status, whether they had children and sources of financial support. Paid employment outside studies was recorded as either "No", "Occasional days per month", "Yes, half-time" (meaning 20 hours/week in Sweden) or "Yes, more than half-time".

Study stress was assessed by the Higher Education Stress Inventory (HESI), comprising 33 items on study conditions, rated on a four-point Likert type scale [3]. A factor analysis revealed 9 factors, together comprising 31 of the items and explaining $41 \%$ of the variance. Of these, 7 were used in the study: negative psychosocial climate (Cronbach's $\alpha$ 0.73), worries about future endurance/capacity (WFEC, Cronbach's $\alpha$ 0.82), insufficient feedback (Cronbach's $\alpha$ 0.66), low commitment (Cronbach's $\alpha$ 0.67), academic workload (Cronbach's $\alpha 0.67$ ), role conflict (Cronbach's $\alpha$ 0.58) and financial concern (Cronbach's 0.57 ), explaining $36 \%$ of the variance. The excluded factors had very low Cronbach's $\alpha$ 's (below $0.38)$.

We measured the burnout dimensions exhaustion (Cronbach's $\alpha$ 0.81) and disengagement (Cronbach's $\alpha$ 0.78 ) by the Oldenburg Burnout Inventory (OLBI), adapted for students [5,17]. Each dimension is computed as means of the pertaining 8 items, scored on a fourpoint Likert scale. For the HESI and the OLBI alike, each factor can take on values between 1 and 4, where higher scores indicate more distress. Each factor was also dichotomised by median split. Cronbach's $\alpha$ 's given above are all computed on this dataset.

Depressive symptoms were assessed by the Major Depression Inventory; a tool validated for screening and diagnostic purposes in general population samples. A score above 27 has been suggested as indicative of a clinically significant depression [18]. Alcohol habits were screened by the Alcohol Use Disorder Identification Test (AUDIT); we defined harmful use as a sum score equal to or above 11, and weekly drinking to intoxication as scoring equal to or above 3 on the third item $[19,20]$.

The respondents were asked to indicate if they assessed themselves as having had mental health problems since entering their studies, whether they considered these problems to be in need of treatment (MHPT), and if and where they had applied for professional help. This measure has been used previously in studies of Norwegian medical students and interns [21].

\section{Statistics}

Since several measures were not normally distributed, we used the Mann-Whitney U-test for comparisons of ratings for stress and burnout, stratifying by sex (except for analyses of stage of education). Odds ratios were computed for proportions, controlling for sex, also enabling estimations of its effect. We used bivariate logistic regression to compute differences in depression and alcohol use between the two subsamples, controlling for sex. Additional analyses, where curricular stage was included as an independent variable, were also performed. Finally, multivariable logistic regression analysis was carried out for assessing the relationships between mental health problems in need of treatment and study stress, burnout and weekly drinking to intoxication. For the latter, the study stress and burnout variables were dichotomised by median split.

\section{Results}

The response rate was $81.6 \%$ at KI (408) and $69.3 \%$ (342) at SSE. The medical students were slightly older; median 24 yrs (Inter Quartile Range, IQR, 22-27) than the business students, 23 yrs (IQR 22-25). At KI, 61.5\% of responders were women, compared to $42.1 \%$ at SSE, reflecting the current proportions of the two programmes. Women were more prone to respond than men at both sites. Further, medical students more commonly lived with a partner and had children than business students. Business students more commonly received economic support from their parents and worked during the semester (Table 1). They also worked longer hours; $17 \%(n=59)$ worked 20 hours/week or more, compared to $5 \%(\mathrm{n}=20)$ of the medical students (OR 4.04, $\mathrm{CI}_{95}$ 2.38; 6.87).

\section{Study stress and burnout}

In Table 2 results on study stress and burnout are shown. Business students of both sexes rated significantly higher than medical students on Negative psychosocial climate, Low commitment and Insufficient feedback. Insufficient feedback was the most highly rated stress factor at both sites. Low commitment and Role conflict received low scores in both samples.

Academic workload was rated higher among female business students than female medical students. At both universities female students scored higher than men on the stress factor Worries about future endurance (WFEC). Business students reported more disengagement 


\begin{tabular}{|c|c|c|c|c|c|c|}
\hline & \multicolumn{2}{|c|}{$\begin{array}{l}\text { KI, Medical students } \\
n=408\end{array}$} & \multicolumn{2}{|c|}{$\begin{array}{l}\text { SSE, Business students } \\
\qquad \mathrm{n}=342\end{array}$} & \multirow[b]{2}{*}{ OR } & \multirow[b]{2}{*}{$\mathrm{Cl}_{95}$} \\
\hline & $\%$ & $\mathrm{n}$ & $\%$ & $\mathbf{n}$ & & \\
\hline Women & 63.5 & 251 & 36.5 & 144 & 2.20 & $1.64 ; 2.95$ \\
\hline Do not receive student funding & 17.5 & 70 & 22.5 & 76 & 0.71 & $0.50 ; 1.02$ \\
\hline Paid employment during semester & 49.5 & 202 & 62.0 & 211 & 0.60 & $0.45 ; 0.81$ \\
\hline Economic support from parents & 25.0 & 102 & 36.8 & 125 & 0.57 & $0.42 ; 0.78$ \\
\hline Married, partnership, partner & 32.6 & 133 & 21.3 & 73 & 1.78 & $1.28 ; 2.48$ \\
\hline With children & 9.1 & 37 & 2.3 & 8 & 4.16 & $1.91 ; 9.07$ \\
\hline
\end{tabular}

$\mathrm{KI}=$ Karolinska Institutet, SSE = Stockholm School of Economics. Odds ratios are computed for group differences.

than medical students. Exhaustion was not significantly different between the universities, but ranked as a more prominent problem than disengagement in both samples.

For medical students, WFEC (Median 2.5 [IQR 2.0;3,0] vs. 3.0 [2.0;3.5], $\mathrm{p}<0.0001)$ and Role Conflict (1.3 $[1.3 ; 1.7]$ vs. $1.3[1.0 ; 2.0], \mathrm{p}=0.032)$ were rated higher in the clinical phase, whereas Workload $(2.3[2.0 ; 3.0]$ vs. $2.0[1.7 ; 2.3], \mathrm{p}<0.0001)$ was higher in the preclinical phase. Business students at the advanced stage were less concerned with Low feedback $(3.0[2.6 ; 3.3]$ vs 2.7 $[2.3 ; 3,0], \mathrm{p}=0.003$ ) than those in the basic years (data on curricular stage not shown in table). In addition, business students at the basic stage rated Exhaustion higher than those at the advanced stage $(2.5$ [2.19;2.9] vs. $2.4[1,9 ; 2.8 . \mathrm{p}=0.030)$ (data not shown in table).

\section{Depression and alcohol}

A depression score above 27 on the MDI was significantly less common among medical students $(9.1 \%, \mathrm{n}=$ 37 vs. $12.3 \%, n=43$ of business students), while controlling for sex. The effect of sex was also significant, showing a higher risk for women (Table 3). There was no association with curricular stage (data not shown).

Harmful alcohol use $(17.2 \%$ [ $=70]$ vs. $31.0 \%$ [ $=106]$; OR $\left.0.55, \mathrm{CI}_{95} 0.37 ; 0.75\right)$ and weekly drinking to intoxication $(7.1 \%,[\mathrm{n}=29]$ v. $\mathrm{s} 14.0 \%[\mathrm{n}=48]$; OR 0.58 , $\mathrm{CI}_{95}$ 0.35; 0.96) were also less common among medical students than among business students. For both outcomes the adjusted effect of sex was significant, where women were less likely to score positive. For depression and weekly drinking to intoxication, no interaction effects of sex and study site were noted. For harmful alcohol use, however, there was a significant interaction effect (OR $\left.0.49, \mathrm{CI}_{95} 0.24 ; 1.00, \mathrm{p}=0.048\right)$, indicating that being a woman and a business student may entail a particular risk. Inclusion of the interaction variable in the model only marginally affected the odds ratios of study site and sex. Curricular stage was not associated with weekly drinking to intoxication, but with harmful alcohol use. When controlling the model on harmful alcohol use for stage (OR $\left.0.66, \mathrm{CI}_{95} 0.47 ; 9,44\right)$, the effect of study site decreased (OR $0.23, \mathrm{CI}_{95} 0.10 ; 0.53$ ), whereas sex (OR $0.45, \mathrm{Cl}_{95} 0.31 ; 0.65$ ) changed only marginally (not shown in table).

\section{Mental health problems in need of treatment and help- seeking}

Table 3 (bottom section) shows the distribution of mental health problems in need of treatment (MHPT) and reported help-seeking. Among medical students, 77.9\% $(\mathrm{n}=317)$ reported no mental health problems in need

Table 2 Descriptive data on study stress and burnout, stratified by sex.

\begin{tabular}{|c|c|c|c|c|c|c|c|c|c|c|c|c|}
\hline & \multicolumn{4}{|c|}{$\mathrm{KI}$, Medical students } & \multicolumn{4}{|c|}{ SSE, Business students } & \multirow{2}{*}{\multicolumn{4}{|c|}{ U-tests }} \\
\hline & & emales & & Males & & emales & & Males & & & & \\
\hline & Med & IQR & Med & IQR & Med & IQR & Med & IQR & $\mathrm{z}_{\mathrm{fem}}$ & $\mathrm{p}_{\mathrm{fem}}$ & $z_{\text {male }}$ & $\mathbf{p}_{\text {male }}$ \\
\hline Negative psychosocial climate & 1.80 & $(1.40-2.20)$ & 1.60 & $(1.40-2.00)$ & 2.00 & $(1.60-2.40)$ & 2.00 & $(1.60-2.40)$ & -5.05 & $<.001$ & -5.74 & $<.001$ \\
\hline Worries about future endurance/capacity & 2.50 & $(2.00-3.00)$ & 2.00 & $(1.50-3.00)$ & 3.00 & $(2.00-3.00)$ & 2.50 & $(1.50-3.00)$ & -0.21 & .837 & -0.28 & .778 \\
\hline Insufficient feedback & 2.67 & $(2.00-3.00)$ & 2.67 & $(2.00-3.00)$ & 3.00 & $(2.33-3.33)$ & 2.67 & $(2.33-3.33)$ & -3.23 & .001 & -3.64 & $<.001$ \\
\hline Low commitment & 1.33 & $(1.00-1.67)$ & 1.33 & $(1.00-1.67)$ & 1.67 & $(1.33-2.00)$ & 1.67 & $(1.33-2.00)$ & -4.95 & $<.001$ & -5.17 & $<.001$ \\
\hline Academic workload & 2.33 & $(2.00-2.67)$ & 2.33 & $(1.67-2.67)$ & 2.67 & $(2.00-3.00)$ & 2.33 & $(1.67-2.67)$ & -4.30 & $<.001$ & -0.01 & .998 \\
\hline Role conflict & 1.33 & $(1.00-2.00)$ & 1.33 & $(1.00-1.67)$ & 1.33 & $(1.08-1.67)$ & 1.33 & $(1.00-1.67)$ & -0.83 & .409 & -0.56 & .573 \\
\hline Financial concerns & 2.00 & $(1.50-2.50)$ & 2.00 & $(1.50-2.50)$ & 2.00 & $(1.50-2.87)$ & 1.75 & $(1.00-2.50)$ & -0.53 & .596 & -2.89 & .004 \\
\hline Disengagement & 1.87 & $(1.50-2.25)$ & 2.00 & $(1.75-2.38)$ & 2.19 & $(1.74-2.63)$ & 2.25 & $(2.00-2.62)$ & -5.51 & $<.001$ & -4.35 & $<.001$ \\
\hline Exhaustion & 2.37 & $(2.00-2.87)$ & 2.25 & $(2.00-2.50)$ & 2.63 & $(2.13-2.87)$ & 2.25 & $(1.87-2.75)$ & -1.98 & .048 & -0.71 & .476 \\
\hline
\end{tabular}

Mann-Whitney U-test. U-tests were performed stratified by sex.

$\mathrm{KI}=$ Karolinska Institutet; SSE = Stockholm School of Economics; Med = Median; IQR = Interquartile range

Medians are derived from factor means of Likert type response scales, range 1-4. 
Table 3 Descriptive data and logistic regressions of current depression, alcohol use, self-reported mental health problems and help-seeking'.

\begin{tabular}{|c|c|c|c|c|c|c|c|c|c|c|c|c|}
\hline & \multicolumn{4}{|c|}{$\begin{array}{c}\mathrm{KI} \\
\text { Medical students }\end{array}$} & \multicolumn{4}{|c|}{$\begin{array}{c}\text { SSE } \\
\text { Business students }\end{array}$} & \multirow[b]{3}{*}{$\mathrm{OR}_{\text {univ }}$} & \multirow[b]{3}{*}{$\mathrm{Cl}_{95}$} & \multirow[b]{3}{*}{$\mathrm{OR}_{\text {sex }}$} & \multirow[b]{3}{*}{$\mathrm{Cl}_{95}$} \\
\hline & \multicolumn{2}{|c|}{ females } & \multicolumn{2}{|c|}{ males } & \multicolumn{2}{|c|}{ females } & \multicolumn{2}{|c|}{ males } & & & & \\
\hline & $\%$ & $\mathbf{n}$ & $\%$ & $\mathrm{n}$ & $\%$ & $\mathbf{n}$ & $\%$ & $\mathbf{n}$ & & & & \\
\hline Depression $^{2}$ & 12.0 & 30 & 4.5 & 7 & 16.7 & 24 & 9.1 & 18 & $0.61^{*}$ & $0.37 ; 0.98$ & $2.31^{*}$ & $1.39 ; 3.85$ \\
\hline Harmful alcohol use $\mathrm{e}^{3}$ & 10.4 & 26 & 28.0 & 44 & 25.0 & 36 & 35.4 & 70 & $0.55^{*}$ & $0.37 ; 0.75$ & $0.44^{*}$ & $0.33 ; 0.63$ \\
\hline Weekly drinking to intoxication ${ }^{4}$ & 3.6 & 9 & 12.7 & 20 & 6.3 & 9 & 19.7 & 39 & $0.58^{*}$ & $0.35 ; 0.96$ & $0.25^{*}$ & $0.15 ; 0.46$ \\
\hline No mental health problems of importance & 73.3 & 184 & 84.7 & 133 & 72.9 & 105 & 86.4 & 171 & 0.97 & $0.67 ; 1.40$ & $0.46^{*}$ & $0.32 ; 0.68$ \\
\hline Have not sought help, even if needed & 8.4 & 21 & 4.5 & 7 & 9.7 & 14 & 8.1 & 16 & 0.67 & $0.37 ; 1.21$ & 1.03 & $0.56 ; 1.90$ \\
\hline Have consulted student health services & 6.8 & 17 & 4.5 & 7 & 2.8 & 4 & 1.0 & 2 & $3.39^{*}$ & $1.32 ; 8.71$ & 1.19 & $0.51: 2.78$ \\
\hline Have consulted GP & 2.8 & 7 & 3.4 & 6 & 1.4 & 2 & 1.0 & 2 & 3.10 & $0.96 ; 10.05$ & 0.54 & $0.20 ; 1.49$ \\
\hline Have consulted psychiatrist/psychologist & 8.0 & 20 & 2.5 & 4 & 13.2 & 19 & 3.5 & 7 & 0.53 & $0.28 ; 1.01$ & $1.02^{*}$ & $1.44 ; 6.35$ \\
\hline Have been admitted to psychiatric clinic & 0.4 & 1 & 0 & 0 & 0.7 & 1 & 0 & 0 & 0.54 & $0.03 ; 8.73$ & - & - \\
\hline
\end{tabular}

Logistic regression for each variable over student group (reference category is SSE), controlling for sex (reference category is men). Adjusted odds ratios for university and as well as the covariate sex are presented. ${ }^{*}$ Indicates significant group difference according to $95 \%$ confidence intervals. ${ }^{1}$ Help-seeking is reported as at any time during the course of studies. ${ }^{2}$ Major depression Inventory (MDI) score $>27$. ${ }^{3}$ Alcohol Use Disorder Identification Test score (AUDIT) $\geq 11$. 4 Item 3 of the AUDIT

of treatment, as compared to $80.7 \%(n=276)$ among business students (not significant). Men were more likely to report no MHPT. The two student groups differed in their choice of help-seeking only with regard to student health services, which were more often sought by medical students, and there was a minor but significant tendency for women to have sought specialised help from psychologists or psychiatrists more often than men. The overall proportion of students having refrained from seeking help even if they considered they needed to, was $7.7 \%(\mathrm{n}=58)$, with no sex or student group difference.

\section{Factors associated with mental health problems in need of treatment}

To assess whether MHPT was associated with burnout, study stress or alcohol habits, we performed a multivariable analysis. MHTP was entered as a dependent variable and study stress factors, burnout factors and weekly drinking to intoxication as independent variables, controlling for gender and student group, see Table 4 . Being a woman, having rated above median on Low commitment, Financial concerns and Exhaustion were all independently associated with having mental health problems in need of treatment. Additional analyses, controlling for having children, a steady partner or paid employment, did not improve the model or considerably change the effect of the initially entered variables.

\section{Discussion}

This study showed that the business students perceived more study stress and were more disengaged from their studies than the medical students. Female students of both categories were more distressed. Further, especially female business students were at risk for harmful alcohol habits. The prevalence of mental health problems in need of treatment and help-seeking did not differ between the two student groups. While medical students are often claimed to be particularly subject to high levels of distress $[1,12,22,23]$, our present results align with some previous findings from comparative studies $[10,11]$. The distress repeatedly noted in medical students may thus be a phenomenon present among most university students [9] or even young people in general $[7,8]$.

The higher levels of study stress and disengagement may apply to curricular and/or cultural differences

Table 4 Multivariable analysis of effect on MHPTof study stress, burnout and alcohol use, controlling for student group and sex

\begin{tabular}{|c|c|c|c|}
\hline & OR & $95 \%$ C.I. & p \\
\hline Student group $(\mathrm{SSE}=1, \mathrm{KI}=0$ ) & 1.39 & $0.92 ; 2.08$ & .114 \\
\hline Gender (women = 1) & 2.01 & $1.32 ; 3.04$ & .001 \\
\hline Negative psychosocial climate ${ }^{\dagger}$ & 1.38 & $0.86 ; 2.22$ & .176 \\
\hline Worries about future endurance/capacity ${ }^{\dagger}$ & 1.36 & $0.89 ; 2.10$ & .158 \\
\hline Insufficient feedback ${ }^{\dagger}$ & 0.96 & $0.63 ; 1.47$ & .860 \\
\hline Low commitment $^{\dagger}$ & 1.95 & $1.09 ; 3.51$ & .025 \\
\hline Academic workload $^{\dagger}$ & 0.73 & $0.47 ; 1.14$ & .167 \\
\hline Role conflict $^{\dagger}$ & 1.42 & $0.89 ; 2.27$ & .146 \\
\hline Financial concerns ${ }^{\dagger}$ & 1.81 & $1.18 ; 2.80$ & .007 \\
\hline Disengagement $^{\dagger}$ & 1.44 & $0.91 ; 2.28$ & .121 \\
\hline Exhaustion $^{\dagger}$ & 2.56 & $1.60 ; 4.10$ & .000 \\
\hline Weekly drinking to intoxication & 1.05 & $0.55 ; 2.01$ & .880 \\
\hline
\end{tabular}

Logistic regression analysis. Cox \& Snell $R^{2} 0.12$, Nagelkerke $R^{2} 0.19$ MHTP $=$ Mental health problems in need of treatment, $\mathrm{KI}=$ Karolinska Institutet

SSE $=$ Stockholm School of Econonomics

${ }^{\dagger}$ variable dichotomised by median split, scale range for all 1-4. 
between the two schools. The absence of graded marks at medical school in Sweden may actually serve as a buffer for study stress, as it may reduce competition and enhance peer support and thus effect the ratings of factors Negative psychosocial climate (for both sexes) and Academic workload (for women). Social support is a well-known moderator of stress, according to the demand-control model, especially so for women [24]. In addition, medical students generally stay together in the same class throughout the university career, while the business students do not have the same group cohesion. Although rated higher among business students of both sexes, the factor Insufficient feedback yielded the highest scores at both sites. Feedback is central for learning and motivation [25], thus possibly also affecting the variables Low commitment and Disengagement from studies, which were also more prominent among business students. Improving feedback strategies may be an important target for interventions, although our results do not imply that it would have a specific effect on perceived mental health.

There was no difference between the student groups with regard to exhaustion levels. One of few studies, from the US, found that business students had elevated exhaustion levels compared to "high-exhaustion" occupations, such as physicians, policemen and teachers, which were in turn associated with high coursework involvement. In contrast to the present study, this was performed during a high-stress period of final exams and no gender differences were recorded [26]. The effect of curricular stage on study stress and burnout differed between sites. For business students only Low feedback and Exhaustion differed by stage, and they were less problematic in the advanced phase; while medical students in the clinical stage reported more Worries about future endurance/capacity and Role conflict. This confirms previous findings from our group [3,27].

Self reported depressive symptoms were highly prevalent in the present samples, as in other studies of medical students $[12,28]$. The medical students did not, however, show the highest rates in our study. Independent of student group, women were more often depressed, which corresponds to the situation in the general population and Swedish university students $[9,29]$. In the general population, young women have comparably higher prevalence of self-rated depression than the older age groups [20]. We did not find that depression was related to stage in any of the two samples, as opposed to previous findings [30]. Medical students at the transition into clinical courses have been shown to be especially at risk for depressive reactions and stress [31], but this particular phase was not targeted by our design.
Harmful use of alcohol was high for men in both samples (28\% at KI and 35\% at SSE) and particularly notable among female business students (25\%). According to a recent Swedish study, the prevalence of harmful alcohol use by the same measure was considerably lower, $7 \%$, in Stockholm residents aged 20-34 years [20], thus close to the levels among female medical students. Among Swedish students in general, however, a high involvement of alcohol is known; female university students have their peak of alcohol consumption earlier than male students, and for both genders use of alcohol decreases during university studies [32], which was confirmed in our data. Since the alcohol habits of medical students may influence their perception of practise, where students with high alcohol intake are less inclined to counsel patients on alcohol use, [33], the recorded high prevalence of male medical students is of concern. The high alcohol consumption among business students of both sexes may be related to the different university cultures. While business students from early on engage in representation with the business sector, medical students are confronted with alcohol as a health risk. Since the study was performed, this issue has been addressed actively at the SSE, with programmes directed to enhance awareness of specific problems among female students and revisions of alcohol policies in SSE-related activities.

The prevalence of mental health problems in need of treatment (MHPT) did not differ between the groups and was comparable to findings from a Norwegian study of senior medical students. As opposed to our findings, however, no gender differences were found in the Norwegian sample [34]. Further, our results did not support the assumption that medical students are particularly negative to help-seeking for mental distress $[16,28,35]$, at least not compared to business students. Medical students may have a lower threshold for consulting a professional, due to the availability of student health services on the KI campus, the like of which the SSE students do not have access to. The proportion of medical students $(6.9 \%)$ that did not seek help although they thought they needed it was at level with the $6.2 \%$ among final year medical students in a Norwegian study using the same inventory [21]. Low commitment and Financial concerns as well as Exhaustion were associated with MHPT. We controlled for factors that might influence perceived stress, such as having the responsibility for children or working along with studies, but these did not add any explanatory effect. Weekly drinking to intoxication was not associated with perceived mental distress, indicating that the potentially harmful alcohol habits may not yet have rendered any negative outcomes. 
There were some limitations to this study. Business students had a somewhat lower response rate. Low response rates may give a shortfall of severely distressed individuals [36] in which case, however, the differences we found would be even more pronounced. It may be argued that medical students are less willing to report symptoms of mental distress and that they also underestimate their alcohol consumption. From the discussions with the Student Associations of both universities ahead of the study, the opposite was rather expected, and the problem of under-reporting is rarely otherwise addressed in studies of medical students. Some of the measured study stress factors had low internal consistency, which may indicate some instability over the two student populations. A measure of personality in the survey would have been valuable. Although the two schools attract students of similar characteristics concerning marks and ambition, they may differ with regard to personality traits, which may affect the students' sensitivity to stress [5,37]. It is, however, possible that the study stress measure WFEC may rather reflect a personality aspect than an actual stressor. It did not differ between student groups, but women from both universities reported greater concerns about future endurance in their professional life than their male colleagues. This finding is consistent with gender differences found in studies of worry in the general population [38]. We had no data on exact year of schooling, which is known to affect distress in medical students. Nevertheless, we think the data on curricular stage may be perceived as a proxy. Finally, the generalisability of our findings is uncertain. Although the comparative sample was chosen with great deliberation and considered appropriate, the influence of cultural, curricular and local factors on the findings cannot be ruled out. The lack of comparative studies in the field is striking; for the sake of generalisability, future research should preferably include national and multicentre studies.

\section{Conclusions}

We found that medical students were less affected with mental distress and harmful alcohol use than business students. The frequently stated high levels of stress among medical students may thus not be exceptional compared to other student populations. A higher awareness of a healthy lifestyle, the absence of stress from graded marks and a more socially cohesive structure of medical education may act as beneficial factors. Screening for mental distress at local universities to evaluate the need for preventive measures and improved availability of local student health services would be valuable.

\section{List of abbreviations}

HESI: Higher Education Stress Inventory; WFEC: Worries about Future Endurance/Capacity; OLBI: Oldenburg Burnout Inventory; AUDIT: Alcohol Use Disorder Identification Test; IQR: Interquartile Range; SSE: Stockholm School of Economics; Kl: Karolinska Institutet; MHTP: Mental Health Problems in need of Treatment; OSCE: Objective Structured Clinical Examination

\section{Acknowledgements and funding}

In addition to all participants, we thank Cecilia Frietsch, Rita Dubbelman and Christina Lindahl-Zander as well as the Students' Union at SSE for support and great collaboration. Funding was received from the Board of Education at Karolinska Institutet.

\section{Author details}

${ }^{1}$ Department of Clinical Neuroscience, Centre of Psychiatric Research, St. Goran, Karolinska Institutet, Stockholm, Sweden. ${ }^{2}$ Sundsvalls Sjukhus [Sundsvall's Hospital], Sundsvall, Sweden. 3 Department of Women's Health, Sodersjukhuset, Stockholm, Sweden.

\section{Authors' contributions}

BR arranged funding and planned the study. CN took part in planning the study, carried out the data collection and initial statistical analyses and wrote a first draft of the manuscript. ES interpreted data. MD planned the study, performed statistical analyses and wrote the manuscript. All authors took part in data interpretation, revision of the manuscript and have read and approved the final manuscript.

\section{Authors' information}

BR is Professor of Psychiatry at Kl, his main research field is within

Suicidology. MD is Senior Lecturer in Psychiatry at Kl, her main research field is within Student Health. CN was a medical student at $\mathrm{KI}$ at the time of data collection, currently doing her preregistration year. ES is an $\mathrm{MD}$, with a current position as resident in Obstetrics/Gynaecology.

\section{Competing interests}

Marie Dahlin and Bo Runeson both teach at Karolinska Institutet medical school and funding was received from the Board of Education of Karolinska Institutet, which has had no influence on the design, analyses or results of the study.

Received: 29 June 2011 Accepted: 7 November 2011

Published: 7 November 2011

\section{References}

1. Firth J: Levels and sources of stress in medical students. Br Med J (Clin Res Ed) 1986, 292:1177-1180.

2. Stewart SM, Betson C, Lam TH, Marshall IB, Lee PW, Wong CM: Predicting stress in first year medical students: a longitudinal study. Med Educ 1997, 31:163-168.

3. Dahlin $\mathrm{M}$, Joneborg $\mathrm{N}$, Runeson B: Stress and depression among medical students: a cross-sectional study. Medical Education 2005, 39:594-604.

4. Enns MW, Cox BJ, Sareen J, Freeman P: Adaptive and maladaptive perfectionism in medical students: a longitudinal investigation. Medical Education 2001, 35:1034-1042.

5. Dahlin M, Joneborg N, Runeson B: Performance-based self-esteem and burnout in a cross-sectional study of medical students. Med Teach 2007 29:43-48.

6. Jonsson $\mathrm{M}$, Ojehagen $\mathrm{A}$ : [Medical students experience more stress compared with other students]. Lakartidningen 2006, 103:840-843.

7. Smith RP, Larkin GL, Southwick SM: Trends in U.S. emergency department visits for anxiety-related mental health conditions, 1992-2001. J Clin Psychiatry 2008, 69:286-294.

8. Martin A, Leslie D: Psychiatric inpatient, outpatient, and medication utilization and costs among privately insured youths, 1997-2000. Am J Psychiatry 2003, 160:757-764.

9. Vaez M, Ponce de Leon A, Laflamme L: Health-related determinants of perceived quality of life: a comparison between first-year university students and their working peers. Work 2006, 26:167-177.

10. Singh $G$, Hankins $M$, Weinman JA: Does medical school cause health anxiety and worry in medical students? Medical Education 2004, 38:479-481.

11. Helmers KF, Danoff D, Steinert $Y$, Leyton M, Young SN: Stress and depressed mood in medical students, law students, and graduate students at McGill University. Acad Med 1997, 72:708-714. 
12. Aktekin M, Karaman T, Senol YY, Erdem S, Erengin H, Akaydin M: Anxiety, depression and stressful life events among medical students: a prospective study in Antalya, Turkey. Medical Education 2001, 35:12-17.

13. Rosvold EO, Bjertness E: Illness behaviour among Norwegian physicians. Scand J Public Health 2002, 30:125-132.

14. Chew-Graham CA, Rogers A, Yassin N: 'I wouldn't want it on my CV or their records': medical students' experiences of help-seeking for mental health problems. Medical Education 2003, 37:873-880.

15. Hooper $C$, Meakin $\mathrm{R}$, Jones $M$ : Where students go when they are ill: how medical students access health care. Med Educ 2005, 39:588-593.

16. Brimstone R, Thistlethwaite JE, Quirk F: Behaviour of medical students in seeking mental and physical health care: exploration and comparison with psychology students. Med Educ 2007, 41:74-83.

17. Demerouti E, Bakker AB, Nachreiner F, Schaufeli WB: The job demandsresources model of burnout. Journal of Applied Psychology 2001, 86:499-512.

18. Olsen L, Jensen D, Noerholm V, Martiny K, Bech P: The internal and external validity of the Major Depression Inventory in measuring severity of depressive states. Psychological Medicine 2003, 33:351-356

19. Saunders JB, Aasland OG, Babor TF, de la Fuente JR, Grant M: Development of the Alcohol Use Disorders Identification Test (AUDIT): WHO Collaborative Project on Early Detection of Persons with Harmful Alcohol Consumption-II. Addiction 1993, 88:791-804.

20. Dahlberg K, Forsell Y, Damstrom-Thakker K, Runeson B: Mental health problems and healthcare contacts in an urban and a rural area. Comparisons of two Swedish counties. Nord J Psychiatry 2007, 61:40-46.

21. Tyssen R, Rovik JO, Vaglum P, Gronvold NT, Ekeberg O: Help-seeking for mental health problems among young physicians: is it the most ill that seeks help? - A longitudinal and nationwide study. Soc Psychiatry Psychiatr Epidemiol 2004, 39:989-993.

22. Dyrbye LN, Thomas MR, Shanafelt TD: Medical student distress: causes, consequences, and proposed solutions. Mayo Clin Proc 2005, 80:1613-1622.

23. Saipanish R: Stress among medical students in a Thai medical school. Medical Teacher 2003, 25:502-506.

24. Theorell $\mathrm{T}$ : The demand-control-support model for studying health in relation to the work environment - an interactive model. In Behavioural medicine approaches to cardiovascular disease prevention. Edited by: OrthGomér K, Schneiderman N. Lawrence Erlbaum Associates; 1996:69-85.

25. Nicol DR, Macfarlane-Dick D: Formative assessment and self-regulated learning: a model and seven principles of good feedback practice. Studies in Higher Education 2006, 31:199-218.

26. Law DW: Exhaustion in university students and the effect of coursework involvement. J Am Coll Health 2007, 55:239-245.

27. Dahlin ME, Runeson B: Burnout and psychiatric morbidity among medical students entering clinical training: a three year prospective questionnaire and interview-based study. BMC Med Educ 2007, 7:6.

28. Givens $\lrcorner$, Tjia J: Depressed medical students' use of mental health services and barriers to use. Academic Medicine 2002, 77(9):918-21.

29. Mattisson C, Bogren M, Nettelbladt P, Munk-Jorgensen P, Bhugra D: First incidence depression in the Lundby Study: a comparison of the two time periods 1947-1972 and 1972-1997. J Affect Disord 2005, 87:151-160.

30. Rosal MC, Ockene IS, Ockene JK, Barrett SV, Ma Y, Hebert JR: A longitudinal study of students' depression at one medical school. Academic Medicine 1997, 72:542-546.

31. Compton MT, Carrera J, Frank E: Stress and depressive symptoms/ dysphoria among US medical students: results from a large, nationally representative survey. J Nerv Ment Dis 2008, 196:891-897.

32. Andersson $C$, Johnsson $\mathrm{KO}$, Berglund $\mathrm{M}$, Ojehagen $\mathrm{A}$ : Alcohol involvement in Swedish University freshmen related to gender, age, serious relationship and family history of alcohol problems. Alcohol Alcohol 2007, 42:448-455.

33. Frank E, Elon L, Naimi T, Brewer R: Alcohol consumption and alcohol counselling behaviour among US medical students: cohort study. BMJ 2008, 337:a2155.

34. Tyssen R, Vaglum P, Gronvold NT, Ekeberg O: Factors in medical school that predict postgraduate mental health problems in need of treatment. A nationwide and longitudinal study. Med Educ 2001, 35:110-120.

35. Tjia J, Givens JL, Shea JA: Factors associated with undertreatment of medical student depression. J Am Coll Health 2005, 53:219-224.
36. Lundberg I, Damstrom Thakker K, Hallstrom T, Forsell Y: Determinants of non-participation, and the effects of non-participation on potential cause-effect relationships, in the PART study on mental disorders. Soc Psychiatry Psychiatr Epidemiol 2005, 40:475-483.

37. McManus IC, Keeling A, Paice E: Stress, burnout and doctors' attitudes to work are determined by personality and learning style: a twelve year longitudinal study of UK medical graduates (Electronic). BMC Med 2004, 2:12.

38. Robichaud M, Dugas MJ, Conway M: Gender differences in worry and associated cognitive-behavioral variables. Journal of Anxiety Disorders 2003, 17:501-516.

\section{Pre-publication history}

The pre-publication history for this paper can be accessed here: http://www.biomedcentral.com/1472-6920/11/92/prepub

doi:10.1186/1472-6920-11-92

Cite this article as: Dahlin et al:: Mental distress, alcohol use and helpseeking among medical and business students: a cross-sectional comparative study. BMC Medical Education 2011 11:92.

\section{Submit your next manuscript to BioMed Central and take full advantage of:}

- Convenient online submission

- Thorough peer review

- No space constraints or color figure charges

- Immediate publication on acceptance

- Inclusion in PubMed, CAS, Scopus and Google Scholar

- Research which is freely available for redistribution

Submit your manuscript at www.biomedcentral.com/submit
C Biomed Central 